\title{
CHOLINERGIC NEURONS OF THE CHICK CILIARY GANGLIA EXPRESS ADRENERGIC TRAITS IN VIVO AND IN VITRO ${ }^{1}$
}

\author{
G. TEITELMAN, T. H. JOH, L. GRAYSON, D. H. PARK, D. J. REIS, AND L. IACOVITTI \\ Laboratory of Neurobiology, Cornell University Medical College, New York, New York 10021
}

Received October 7, 1983; Revised June 18, 1984; Accepted June 22, 1984

\begin{abstract}
In this study, we sought to determine whether neurons of the chick embryo ciliary ganglia (CG), a parasympathetic cholinergic ganglia, can express catecholaminergic (CA) traits. To accomplish this, we used immunocytochemical techniques to examine the presence of the CA enzymes tyrosine hydroxylase (TH) and phenylethanolamine $N$-methyltransferase (PNMT) in CGs removed from chick embryo at day 8 of development (E8). Few neurons containing TH but not PNMT were found in the E8 CG. To examine whether CG neurons express CA enzymes in vitro, CGs removed from E8 chick embryo were dissociated and kept in culture for 3 to 12 days. In $50 \%$ of the culture dishes, some neurons contain TH or PNMT after 5 days in vitro. In an equal proportion of culture plates, CG neurons did not express the enzymes. To determine whether the proportion of CG neurons expressing TH or PNMT is increased by tissue influences, ganglion cells were co-cultured with notochord. In $90 \%$ of the co-culture experiments, most neurons present in the culture dishes stained with TH or PNMT after 5 days in vitro. To test for the presence of aromatic $\mathbf{L}$-amino acid decarboxylase (AADC), another CA enzyme, cultures of CGs and CGs plus notochord were incubated with levodopa and processed for the detection of CA histofluorescence. Dopamine histofluorescence was present in all neurons after 3 days in vitro irrespective of the presence of notochord, suggesting that the expressions of TH and PNMT and that of AADC are differentially regulated. This study, therefore, demonstrates that cholinergic neurons of the CG contain CA enzymes in vivo and in vitro and that the proportion of neurons expressing $\mathrm{C} \Lambda$ traits during development in vitro can be increased by environmental cues such as those released by the notochord.
\end{abstract}

It is now well established that the neurotransmitter phenotype of the neural crest derivatives which populate the sympathetic organs remains labile even after the cells have withdrawn from the cell cycle and synthesize putative neurotransmitters. Thus, postmitotic rat sympathetic neurons, in addition to synthesizing, storing, and releasing catecholamines, can synthesize acetylcholine and form cholinergic synapses upon one another when grown under appropriate tissue culture conditions (Bunge et al., 1978; Furshpan et al., 1976; Higgins et al., 1981; Iacovitti et al., 1981; Patterson, 1978).

These findings raise questions as to whether neurons of the parasympathetic system also exhibit phenotypic plasticity. That cells of the cholinergic parasympathetic ciliary ganglion (CG) can express traits characteristic of adrenergic neurons has been suggested by the studies of LeDouarin et al. (1978). In these experiments, quail embryonic CG was transplanted into the neural axis of a younger chick embryo. Following transplantation, cells of the CG populated sympathetic organs wherein they expressed catecholamine (CA) histofluorescence. However, this study does not establish whether cells containing CA properties are normally present in the CG during development in vivo and merely maintain that expression in the sympathetic organs of the avian chimaeras or whether the CA

\footnotetext{
${ }^{1}$ This work was supported by National Institutes of Health Grant HL 18974 and National Science Foundation Grant PCN 8303019. We wish to thank Rarbara Strauss and I inda Rosenbluth for their assistance in preparing this manuscript.
}

properties are expressed for the first time by cells of the ganglion. Moreover, since it was postulated that the nonneuronal cells of the ganglia are responsible for the histofluorescence observed in the sympathetic ganglia of the chimaeric embryo, the question regarding the neurotransmitter plasticity of parasympathetic neurons still remained unanswered.

In the present study, we have therefore sought to determine, by immunocytochemical, histofluorescent, and radioautographic methods, whether the cholinergic neurons of the CG contain $\mathrm{CA}$ enzymes in vivo and in vitro and whether, in vitro, these enzymes are present in proliferating or postmitotic cells. The enzymes examined were: tyrosine hydroxylase $(\mathrm{TH})$, responsible for the conversion of $\mathbf{L}$-tyrosine into levodopa ( $\mathrm{L}$ DOPA); aromatic L-amino acid decarboxylase (AADC) which catalyzes the biosynthesis of dopamine from L-DOPA; and phenylethanolamine $N$-methyltransferase (PNMT) required for the transformation of norepinephrine into epinephrine.

We shall demonstrate that: (1) in vivo, a small number of $\mathrm{CG}$ neurons contain $\mathrm{TH}$ and that, in vitro, they also express PNMT and probably AADC; (2) in vitro, the proportion of neurons expressing $\mathrm{TH}$ and PNMT increases dramatically when the ganglia is co-cultured with notochord, a transient axial structure implicated in the normal signaling of adrenergic differentiation (Cohen, 1972; Norr, 1973; Teillet et al., 1978); and (3) in vitro, TH immunoreactivity is expressed by postmitotic neurons. 


\section{Materials and Methods}

\section{Histology}

Fertile white Leghorn chick eggs were obtained fresh from the hatchery and placed in a force-draft incubator at 38 to $39^{\circ} \mathrm{C}$. Embryos were staged according to the method of Hamburger and Hamilton (1951).

Embryos were removed from fertilized eggs after 8 days of incubation, and immersed in fixative solution ( $4 \%$ formaldehyde generated from paraformaldehyde in $0.1 \mathrm{M}$ sodium phosphate buffer, $\mathrm{pH} 7.2$ ). The CGs were removed, fixed for $2 \mathrm{hr}$, washed twice with $0.1 \mathrm{M}$ phosphate buffer, embedded in a $30 \%$ sucrose solution overnight and sectioned at $16 \mu \mathrm{m}$ in a cryostat microtome. The sections were thawmounted onto glass slides precoated with a $1 \%$ gelatin solution.

\section{Immunohistochemistry}

The procedures for preparation of antibodies to TH and PNMT have been described previously (Joh and Ross, 1983). Antibodies were determined to be specific by their ability to precipitate enzyme activity from a crude tissue homogenate and by the production of a single immunoprecipitin arc when analyzed by immunodiffusion and immunoelectrophoresis against a crude antigen preparation. In addition to these tests, the highly sensitive technique of Western blotting was used to establish antibody specificity. A crude homogenate prepared from rat or bovine brain and adrenal gland tissue, PC2 pheochromocytoma cells or human neuroblastoma cells SR-N-BE (2) was fractionated on SDS-acrylamide gels (Laemmli, 1980), and transferred to nitrocellulose filters according to the method of Towbin et al. (1979). Nonspecific sites on the nitrocellulose were blocked with $2.5 \%$ gelatin and the blots were first incubated with primary antisera $\left(4^{\circ} \mathrm{C}\right.$, overnight) diluted from 1:500 to $1: 2000$, rinsed thoroughly, and then incubated with a 1:200 dilution of goat anti-rabbit conjugated horseradish peroxidase. Visualization of antigen-antibody complexes with $3,3^{\prime}$-diaminobenzidine revealed a single band of approximately 60,000 daltons, corresponding to the molecular mass of TH (Fig. 1). Similarly, the antibodies against DBH (not used in this study) and PNMT only cross-reacted with a single protein of 75 and 31 kilodaltons (Fig. 1), which corresponds to the molecular masses of the respective enzymes (Joh et al., 1984). Since this technique will reveal extremely minor contaminant proteins which might react with the antibody, we judged these antisera to be highly specific to the corresponding enzyme.

Antisera to neuronal-specific enolase (NSE) was purchased from Polysciences, Inc. For immunohistochemical staining, the soluble peroxidase-antiperoxidase method of Sternberger (1974) was carried out as described by Teitelman et al. (1978). Essentially, sections were consecutively incubated with: $(a)$ rabbit antibody against bovine PNMT or rat TH (1:500 dilution in $0.2 \mathrm{M}$ Tris-saline plus $1 \%$ goat serum; (b) goat anti-rabbit IgG (1:50 dilution in $0.2 \mathrm{M}$ Tris-saline plus $1 \%$ goat serum; $(c)$ peroxidase-antiperoxidase (PAP) complex (1:50 dilution in $0.2 \mathrm{M}$ Tris-saline plus $1 \%$ goat serum). Bound peroxidase was visualized by incubating the sections with $0.013 \%, 3,3^{\prime}$-diaminobenzidine (DAB, Sigma) and $0.01 \%$ hydrogen peroxidase $(30 \%$ solution). Sections were then dehydrated and mounted in Permount.

\section{Tissue culture}

Collagen was prepared by the method of Bornstein (1958) and polymerized on plastic (Aclar) culture dishes as described by Bunge and Wood (1973). CGs were removed in Leibovitz (L-15) medium from stages 31 to 34 chick embryos by the method of Varon et al. (1979). They were stripped of adherent tissue, but not decapsulated, and incubated in $\mathrm{Ca}^{2+}-\mathrm{Mg}^{2+}$-free Hanks' balanced salt solution for $10 \mathrm{~min}$ at $37^{\circ} \mathrm{C}$ in a clinical rotator (minimum setting). The solution was removed, replaced with a $0.08 \%$ trypsin solution (in $\mathrm{Ca}^{2+}-\mathrm{Mg}^{2+}$-free Hanks' balanced salt solution) and the ganglia were incubated for another $20 \mathrm{~min}$. The ganglia were then rinsed twice in L-15 and placed in culture medium ( $78 \%$ Eagle's minimum essential medium, $10 \%$ heatinactivated horse serum, $10 \%$ chick embryo eye extract) prepared as described by Adler et al. (1979); glucose $(6 \mathrm{mg} / \mathrm{ml})$, glutamine $(204 \mu \mathrm{g} /$ $\mathrm{ml}$ ), and penicillin/streptomycin (100 units/ml). Dissociation was accomplished by trituration through a reduced bore borosilicate glass pipette. The cell suspension was then passed through a sterile $15-\mu \mathrm{m}$ Nitex filter and plated at a density equivalent to $1.5 \mathrm{CG} / \mathrm{dish}$. The number of neurons, identified by their characteristic phase bright cell body, clear nucleus, and prominent nucleolus, was determined using a

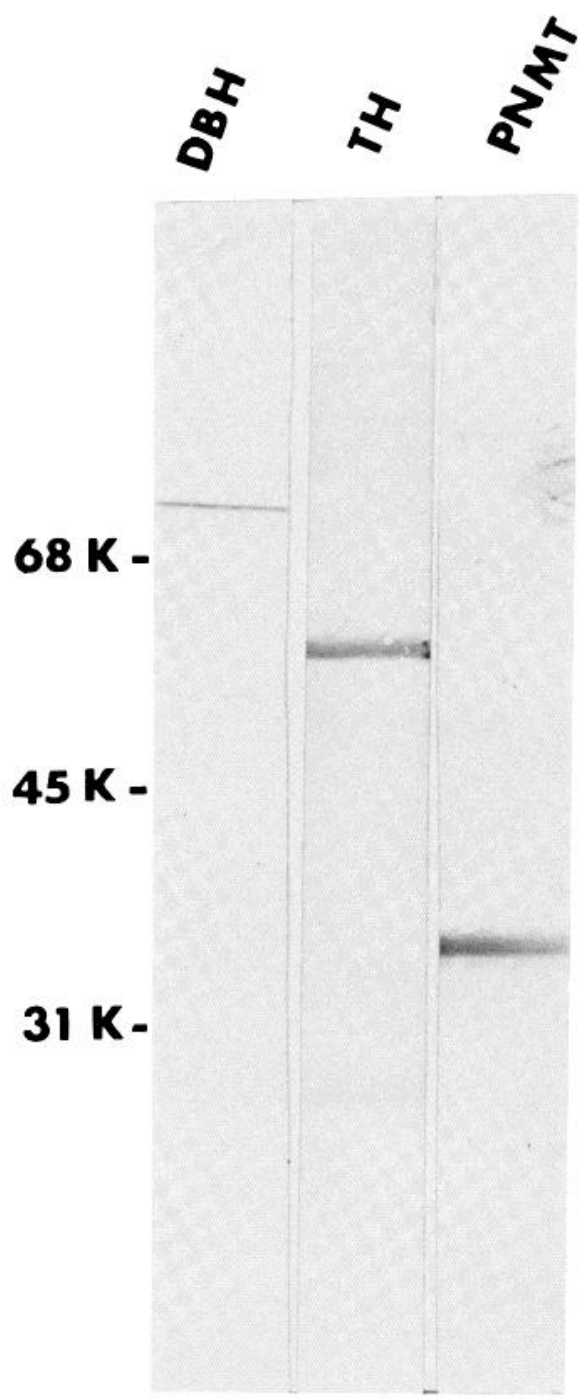

Figure 1. Crude tissue homogenate was separated by SDS-polyacrylamide gel electrophoresis, transferred to nitrocelluose, and stained with antisera as described under "Materials and Methods." Note that each antibody formed a single band which corresponds to the molecular weight of the respective purified enzyme.

gridded dish after 3,5 , and 12 days in culture. At these three time periods, neuronal survival was found to be 90 to $100 \%$ of the number of neurons present in vivo (Landmesser and Pilar, 1974; Pilar et al., 1980).

Notochord(s) were dissected from the trunk of chick embryos of stages 19 to 21 using sharpened stainless steel needles and collected into L-15 medium. Following the dissection procedure, the L-15 solution was replaced by $0.25 \%$ trypsin (in $\mathrm{Ca}^{2+}-\mathrm{Mg}^{2+}$-free Hanks' balanced salt solution) for the 3 to $5 \mathrm{~min}$ at room temperature. The trypsin was then removed and the notochords were rinsed twice with $0.25 \%$ trypsin inhibitor (Sigma) dissolved in Hanks' balanced salt solution, and incubated to $30 \mathrm{~min}$ at $37^{\circ} \mathrm{C}$ in the same solution. After incubation, the notochords were stripped of adherent mesenchyme and transferred to a fresh dish of L-15 solution which was subsequently replaced with culture medium. Notochords were then plated as whole explants on collagen-coated dishes containing culture media. Notochordal explants that were fixed and stained with cresyl violet after 1 or 2 weeks in culture contained large cells exhibiting a typical morphology of notochordal cells at stages 19 to 21 of development (Bancroft and Bellairs, 1976), namely vacuolated cytoplasm and an eccentric nucleus. For immunocytochemical staining, cultures were extensively rinsed in Hanks' balanced salt solution and fixed in $4 \%$ formaldehyde (generated from paraformaldehyde) in $0.1 \mathrm{M}$ phosphate buffer, $\mathrm{pH} 7.2$, for $30 \mathrm{~min}$. Following fixation, whole cultures were stained by the PAP method as described by Iacovitti et al. (1981). In each experiment, cultures proc- 
essed with IgG isolated from pre-immune serum served as controls for nonspecific staining.

\section{Histofluoresence}

Cultures were incubated for $1 \mathrm{hr}$ in L-DOPA (100 $\mu \mathrm{M}$ in L-15) or in L-15 alone, fixed for $30 \mathrm{~min}$ in $4 \%$ formaldehyde plus $0.5 \%$ glutaraldehyde in $0.1 \mathrm{M}$ sodium phosphate buffer, $\mathrm{pH} 7$ (FAGLU solution) (Furness et al., 1977), and dehydrated for $1 \mathrm{hr}$ in a dessicator over phosphorus pentoxide. The cultures were mounted on slides using Entallon mounting medium and examined with a Leitz Orthoplan fluorescent microscope.

In order to test the specificity of the FAGLU technique, the midbrain region was removed from 16-day-old rat embryos, dissociated, and placed in culture. After 5 days in vitro, the cultures were incubated with L-DOPA or vehicle (control cultures) and processed as described above for the detection of CA histofluorescence. In both experimental and control cultures, a few neurons, probably from the monoaminergic nuclei of brain, were histofluorescent. The preincubation step with $\mathrm{L}$ DOPA only increased the intensity of histofluorescence but not the proportion of fluorescent neurons.

\section{Combined immunohistochemistry and radioautography}

In vivo. Chick embryos were injected once with $\left[{ }^{3} \mathrm{H}\right]$ thymidine $(40$ $\mathrm{Ci}$ /egg; specific activity, 50 to $65 \mathrm{Ci} / \mathrm{mmol}$, New England Nuclear Corp.) at day 2 or at day 6 of incubation through a window sawed in the shell. The embryos were fixed at day 8 of development in $4 \%$ formaldehyde (generated from paraformaldehyde) in $0.1 \mathrm{M}$ phosphate buffer; the $\mathrm{CG}$ was removed and postfixed for an additional hour in the same solution, embedded in $30 \%$ sucrose, and sectioned at $16 \mu \mathrm{m}$ in a cryostat. For simultaneous visualization of $\mathrm{TH}$ immunostaining and $\left[{ }^{3} \mathrm{H}\right]$ thymidine labeling, the procedure described by Rothman et al. (1980) was followed. In brief, after the immunocytochemical localization of $\mathrm{TH}$ with diaminobenzidine, the stained sections were washed twice with distilled water, dipped in Kodak NTB2 emulsion (diluted $1: 1$ in water), and maintained at $4^{\circ} \mathrm{C}$ in a light-proof box containing a drying agent (Drierite) for 7 to 10 days. The sections were then developed with Kodak D-19 developer, rinsed, fixed, and mounted with Permount.

In vitro. Cultures of $\mathrm{CG}$ or $\mathrm{CG}$ plus notochord were incubated from the beginning of the culture period in the presence of media containing $0.2 \mu \mathrm{Ci} / \mathrm{ml}$ of $\left[{ }^{3} \mathrm{H}\right.$ ] thymidine (specific activity, $77.1 \mathrm{Ci} / \mathrm{mmol}$ ); or $2 \mu \mathrm{Ci}$ / $\mathrm{ml}$ of $\left[{ }^{14} \mathrm{C} \mid\right.$ thymidine (specific activity, $50.5 \mathrm{mCi} / \mathrm{mmol}$ ). After 5 days, the cultures were fixed with $4 \%$ formaldehyde and processed for immunohistochemical visualization of TH. After the diaminobenzidine step, the rim of the culture dishes was cut and the back surface of the plates was glued to a glass slide so that the culture surface was left exposed. The slides containing the cultures were then dipped twice in undiluted Ilford L-4 emulsion or Kodak NTB2 emulsion, dried, and stored at $5^{\circ} \mathrm{C}$ in the dark for 2 to 4 days. The culture dishes were then developed and fixed as described above. Cultures which had been fogged were uniformly black indicating that the neurons were covered by the emulsion. Cultures that did not receive labeled thymidine were routinely stained and processed for radioautography to rule out chemography.

\section{Results}

Expression of $C A$ enzymes in $C G$ neurons in vivo. CGs removed from chick embryos of stages 31 to 34 were sectioned at $16 \mu \mathrm{m}$ and stained with antibodies to TH or PNMT. Cells containing TH were found in all ganglia, with two to three stained cells in each section. Although difficult to estimate, the number of TH cells in the CG probably did not exceed $0.5 \%$ of the total population of neurons. Stained cells ranged in size from 18 to $22 \mu \mathrm{m}$, usually had long processes which were also stained, and had the characteristic morphology of neurons (Fig. $2 A$ ). The CGs also contained a large number of fine varicose terminals that stained for TH (Fig. $2 B$ ). These terminals, in many cases, surrounded unstained ganglion cells and were more abundant in the periphery than in the center of the ganglionic mass (Fig. 2B). Cells containing PNMT were never seen in the ganglia.

Staining for CA enzymes in $C G$ neurons in vitro. CGs were removed from stages 31 to 34 chick embryos, dissociated, and placed in culture. After $24 \mathrm{hr}$ in vitro, some neurons grew in isolation while others formed small aggregates of two to 10 neurons each. Most neurons formed processes of at least one cell length (15 to $20 \mu \mathrm{m}$ ) and, by $72 \mathrm{hr}$, the neural processes had fasciculated into bundles surrounded by spindle-shaped non-neuronal cells (Fig. 3). Non-neuronal cells were more abundant in areas close to neuronal clusters than in areas of the dish containing single neurons (Fig. $3, A$ and $B$ ). Large triangular cells were also present in the culture dish. These were scarce and, in contrast to the spindle-shaped cells, were localized at random in the culture dish.

During the first 4 days in culture, CG neurons did not stain with TH. After 5 days in vitro, however, between 20 and $30 \%$ of the neurons contained TH. Stained ganglion cells were usually in areas of low density away from non-neuronal cells (Fig. 4). Rarely, a single neuron within a neuronal cluster contained TH immunoreactivity. The proportion of stained to unstained neurons did not increase after 12 days in culture, the longest period examined.

While staining was seen in about half of the culture dishes, in an equal proportion of culture plates $\mathrm{TH}$ was not seen in neurons at any time (Fig. $4 B$ ). In general, cultures of $\mathrm{CG}$ containing recognizable stained neurons had fewer non-neuronal cells than cultures devoid of stained cells. In all instances, however, no significant differences were found in the total number of neurons present in the culture dishes.

Cultures of CGs stained with PNMT antibodies also showed about 20 to $30 \%$ of neurons containing the enzyme (Fig. $4 \mathrm{C}$ ). Stained neurons were seen, as with $\mathrm{TH}$, in about $50 \%$ of the culture dishes stained for PNMT. Since different culture plates were stained with $\mathrm{TH}$ and PNMT, it was not determined whether both enzymes are expressed by the same neurons.

Role of notochord. In preliminary experiments, notochords were isolated and grown alone in vitro. Following explantation, the notochordal cells remained encased in the perinotochordal sheath and did not disperse in culture dish for up to 2 weeks in vitro. Adherent mesenchymal cells proliferated, forming a bed of surrounding fibroblasts. Occasionally, a cell with neuronal morphology was detected. These neurons probably were sympathoblast precursors that had migrated past the neural tube and remained attached to the perinotochordal mesenchyme during dissection. They differed from ciliary neurons in that they lay flatter against the substrate, were multipolar, and had a large nucleus.

To test the role of notochord on the expression of CA enzymes in ciliary neurons, two notochords were explanted into culture dishes. The next day, the dishes were seeded with ganglion cells at a density of $1.5 \mathrm{CG} /$ dish. The addition of notochord did not affect the survival or the appearance of the CG neurons in culture. In $90 \%$ of the experiments in which CG was co-cultured with notochord ( 95 of 107), CG neurons stained for TH (Fig. $4 D$ ) while in $10 \%$ of the co-culture experiments, none of the neurons in the culture dish contained TH immunoreactivity. In the positive experiments, most neurons in the culture dish contained TH immunoreactivity irrespective of whether they were close to or at a distance from the notochord. Staining was first observed after 5 days in vitro and was also seen after 7 and 12 days in culture. TH immunoreactivity was never observed in cells of the notochord or in its accompanying mesenchymal cells. While the intensity of the immunohistochemical reaction varied between different experiments, the intensity of neuronal staining was usually greater in CG neurons at a distance from that in those surrounded by ganglionic non-neuronal cells. In contrast, the presence of perinotochordal mesenchymal cells did not substantially affect the intensity of staining of CG neurons (Fig. $4 D$ ). Since similar differences in staining intensity were seen when cultures were stained with 

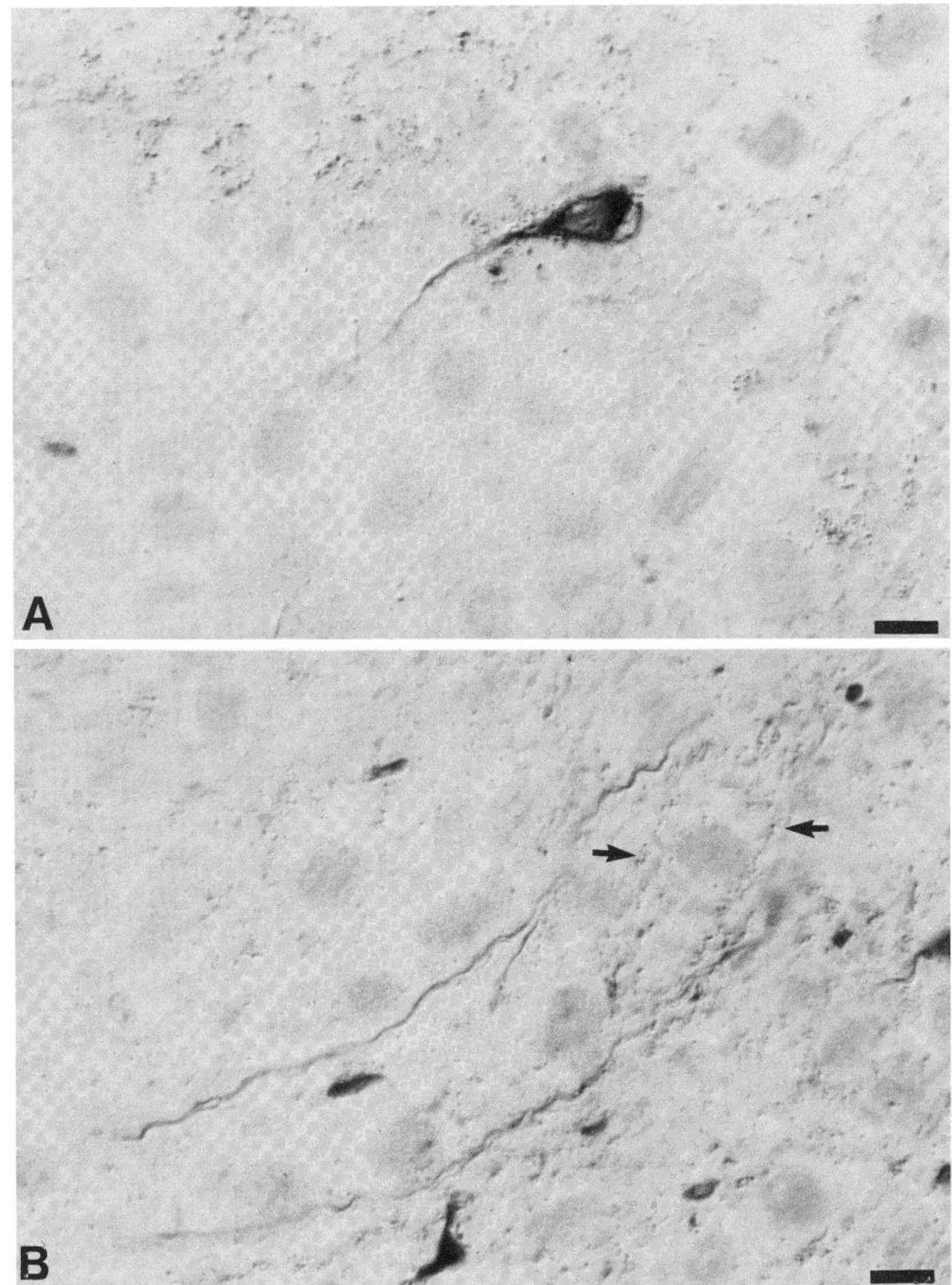

Figure 2. Immunocytochemical localization of TH in cross sections of CG from E8 chick embryo. Note specific localization of immunostaining in cell bodies and processes $(A)$ and in isolated terminals $(B)$, some of them surrounding unstained neuronal cell bodies $($ arrows). Bar $=13 \mu \mathrm{m}$.

antibodies against neuronal-specific enolase, a housekeeping protein, it seems likely that the decrease in staining intensity of neurons surrounded by non-neuronal cells reflects a staining artifact rather than a specific decrease in the concentration of antigen.

The presence of PNMT immunoreactivity in CG neurons cultured in the presence of notochord was also examined. It was found that, as with $\mathrm{TH}$, in the majority of cultures, most neurons stained with PNMT. Since almost $100 \%$ of CG neurons co-cultured with notochord stained with either TH or PNMT, each neuron probably contained both enzymes.
Postmitotic cells express $T H$ in vitro. Next, we sought to determine whether the cells containing $\mathrm{TH}$ in vitro arise from proliferation of the cells containing $\mathrm{TH}$ in vivo or whether the enzyme is expressed by a population of non-neuronal cells or by the cholinergic neurons that initiate the expression of the enzyme once the ganglia is transferred to culture. To examine these possibilities, we first determined whether the neurons containing $\mathrm{TH}$ in vivo are already postmitotic when the ganglia are explanted to culture. To do so, chick embryos were injected with $\left[{ }^{3} \mathrm{H}\right]$ thymidine at days 2 or 6 of development and fixed at day 8 ; the ciliary ganglia were removed and processed for 

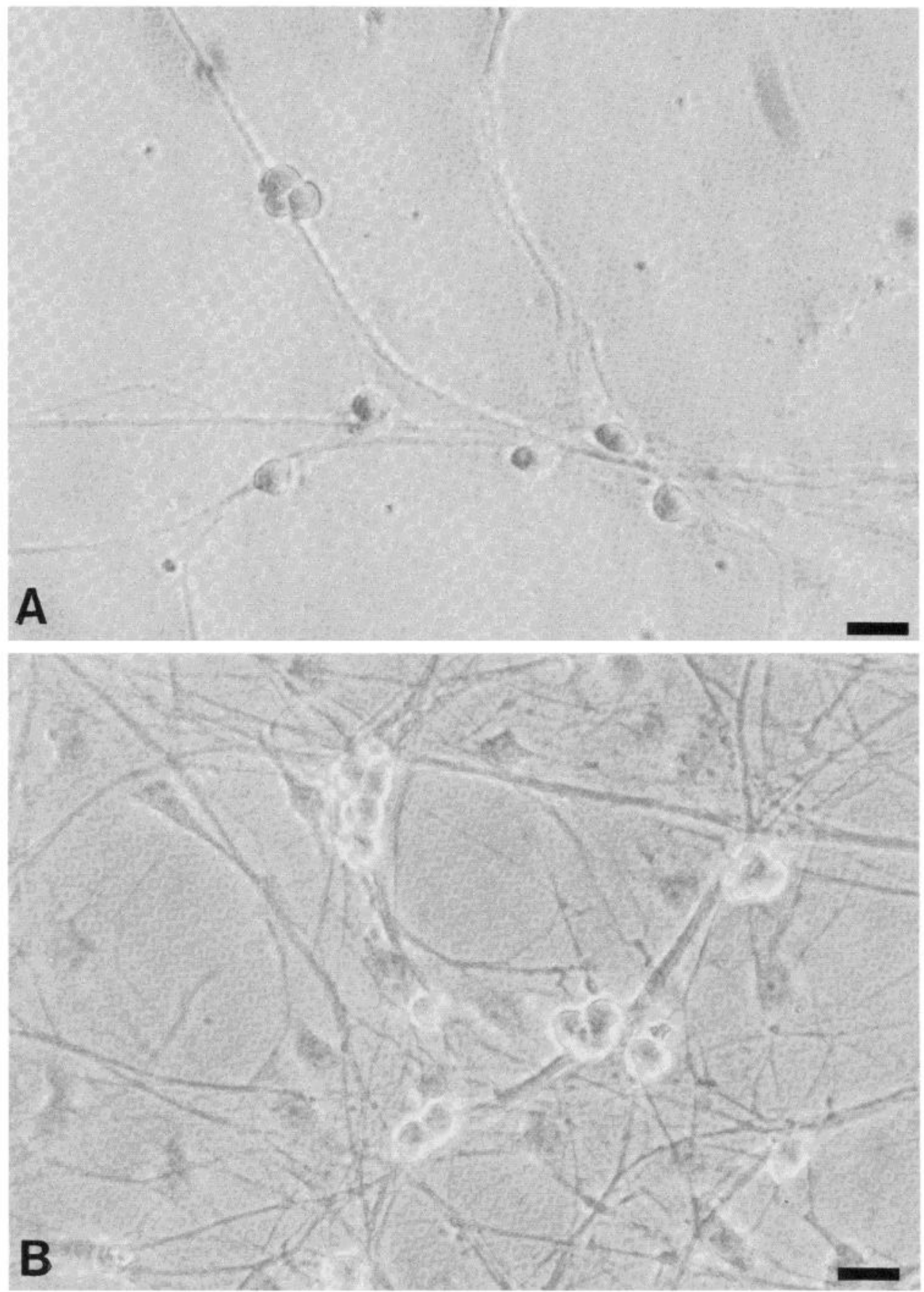

Figure 3 . Neurons of chick ciliary ganglion after 5 days in vitro. Microphotographs are of live cells under phase contrast and were obtained from different areas of the same culture dish. Note that non-neuronal cells are very abundant in $B$ but are almost absent in $A$. Bar $=25$ $\mu \mathrm{m}$. simultaneous visualization of TH immunostaining in the cytoplasm and silver grains over the nuclei. In embryos injected with isotope at day 2 , the cells containing $\mathrm{TH}$ were labeled with $\left[{ }^{3} \mathrm{H}\right]$ thymidine (Fig. $5 A$ ). Silver grains were seen over the nuclei of stained neurons and also non-neuronal cells. In contrast, when embryos were injected with the isotope at day 6 of development, fixed, and processed for observation 2 days later, the nuclei of cells containing $\mathrm{TH}$ as well as those of unstained neurons were unlabeled (Fig. $5 B$ ). In this instance, labeled nuclei were seen surrounding the neuronal cell bodies and probably correspond to non-neuronal cells. These experiments indicate that most neurons of the $\mathrm{CG}$, including those containing $\mathrm{TH}$, withdraw from the cell cycle on or around day 6 of development in vivo.

To test whether the cells containing $\mathrm{TH}$ in vitro arise through proliferation and phenotypic interconversion of non-neuronal precursors, ciliary ganglia removed from E32-34 chick embryo were cultured with or without notochord for 5 days in media containing $\left[{ }^{3} \mathrm{H}\right]$ thymidine. The cultures were then fixed and processed for immunocytochemical staining and radioautography (Fig. 6A). Two populations of cells were seen in the culture dishes: $(a)$ cells labeled with $\left[{ }^{3} \mathrm{H}\right]$ thymidine that lacked $\mathrm{TH}$ immunoreactivity (these cells were flattened against the substrate and had a fibroblast-"like" morphology); and (b) cells that did not incorporate $\left[{ }^{3} \mathrm{H}\right]$ thymidine into their nuclei. This group includes all cells with neuronal morphology. While in cultures of CG plus notochord most cells with unlabeled nuclei contain TH immunoreactivity, the number of stained cells is less in cultures of CG alone. Cells containing $\mathrm{TH}$ immunoreactivity and silver grains were never seen in cultures of CG alone or of CG co-cultured with notochord.

Because ${ }^{3} \mathrm{H}$ is a low energy emitter, only nuclei situated at 

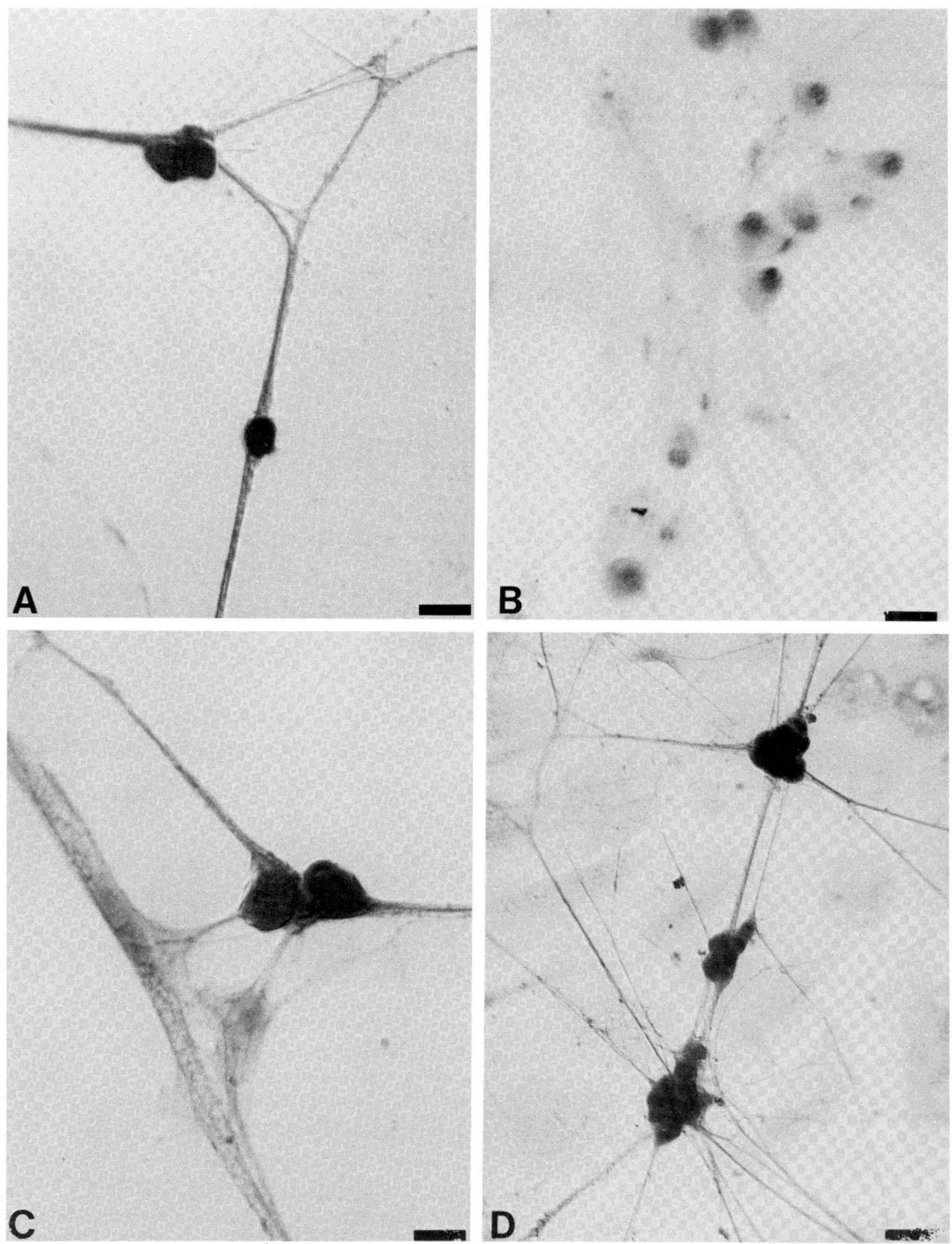

Figure 4. Immunocytochemical localization of CA enzymes in CG neurons maintained 5 days in vitro. A, Some isolated neurons contain TH. $B a r=20 \mu \mathrm{m} . B$, Culture incubated with TH antibodies; some CG neurons lack staining. Bar $=20 \mu \mathrm{m}$. C, CG neurons contain PNMT immunoreactivity. Bar $=13 \mu \mathrm{m} . D$, CG neurons co-cultured with notochord contain TH immunoreactivity. Darkly stained neurons are surrounded by unstained mesenchymal cells derived from the perinotochordal sheath. Note that the presence of mesenchymal cells does not affect the intensity of immunostaining. Bar $=45 \mu \mathrm{m}$. 

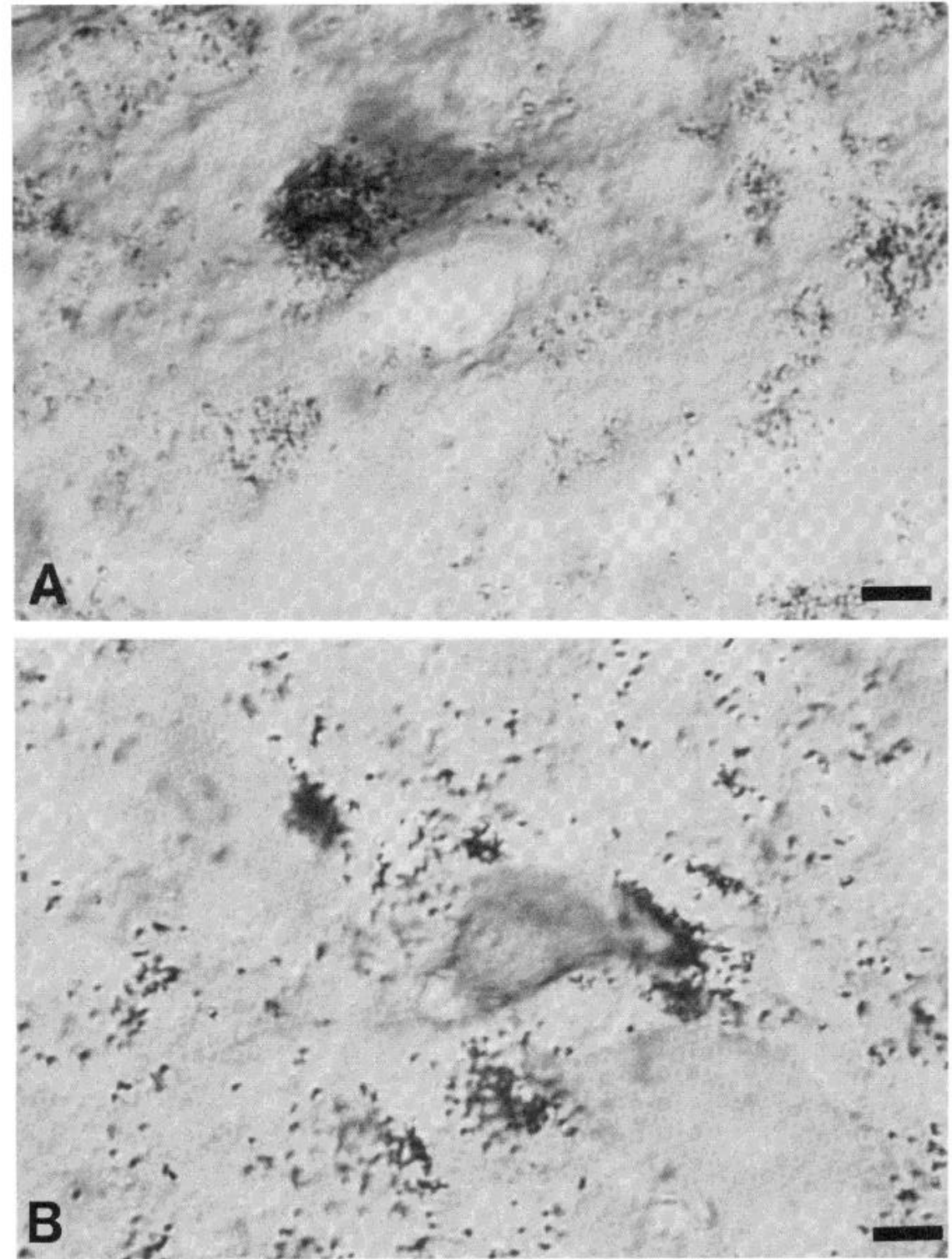

Figure 5. Cross-sections of CGs from E8 chick embryos demonstrating $\mathrm{TH}$ immunoreactivity and labeling by $\left[{ }^{3} \mathrm{H}\right]$ thymidine. $A$, Eggs were injected with $\left[{ }^{3} \mathrm{H}\right]$ thymidine at day 2 of development and killed 6 days later. Note that silver grains are over nucleus of stained cells. $B$, Eggs were injected with $\left[{ }^{3} \mathrm{H}\right]$ thymidine at $\mathrm{E} 6$ and killed 2 days later. Cells stained with $\mathrm{TH}$ antisera lack nuclear labeling with $\left[{ }^{3} \mathrm{H}\right]$ thymidine. Bar $=10 \mu \mathrm{m}$.
$2 \mu \mathrm{m}$ from the photographic emulsion will produce an image. To examine whether the lack of silver grains over the neurons is due to the location of the nuclei at more than $2 \mu \mathrm{m}$ from the cell surface, cultures of CG plus notochord were incubated for 5 days with thymidine tagged with ${ }^{14} \mathrm{C}$, a higher energy emitter, and processed for observation as described above. As shown in Fig. $6 B$, immunoreactive neurons at a distance from nonneuronal cells had unlabeled nuclei while stained neurons next to cells labeled with $\left[{ }^{14} \mathrm{C}\right]$ thymidine had silver grains over their perikarya. However, the density of grains over the stained neurons was always less than that of the surrounding nonneuronal cells and thus probably are due to the wide scattering of the emission characteristic of ${ }^{14} \mathrm{C}$-radioautography (Rogers, 1973). Thus, it is likely that the silver grains over the neurons represent a spillover from their replicating neighbors rather than the result of uptake of isotope into their nuclei. Therefore, the experiments using $\left[{ }^{14} \mathrm{C}\right]-$ and $\left[{ }^{3} \mathrm{H}\right]$ thymidine indicate that most and probably all $\mathrm{CG}$ neurons that express $\mathrm{TH}$ immunoreactivity in vitro are postmitotic.

Histofluorescence. CGs maintained in culture alone or with notochord for 3 to 12 days were incubated in L-15, fixed with FAGLU solution, and processed for histofluorescence. At no time did CG neurons express histofluorescence (Fig. 7A). A second group of culture dishes containing CGs or CGs with notochord were preincubated in a solution of $100 \mu \mathrm{M} \mathrm{L}-\mathrm{DOPA}$ in L-15 cultures media for $1 \mathrm{hr}$ and processed for the detection of histofluorescence. This is, in effect, a test of the conversion of the nonfluorescent precursor L-DOPA into the fluorescent product dopamine by the enzyme AADC and, therefore, is an in situ means of assaying for the presence of the enzyme. After incubation with L-DOPA, most neurons, either isolated or in aggregates, were fluorescent (Fig. $7 B$ ). Catecholamine histofluorescence was also seen in the notochordal explants (Fig. 7) Non-neuronal cells, in contrast, did not fluoresce. Histofluorescence was seen in neurons as early as 3 days in vitro and persisted for up to 12 days in culture, the longest period examined. The presence of notochord in CG cultures did not affect the time of appearance of histofluorescence or the proportion of neurons with histofluorescence. These findings, therefore, suggest that CG neurons maintained in vitro have the capacity to convert L-DOPA into dopamine. Since this step requires catalysis by the enzyme $\mathrm{AADC}$, the results demonstrate that all of the neurons contain the enzyme irrespective of the presence of notochord.

\section{Discussion}

In this study, we sought to determine whether the cholinergic neurons of the chick ciliary ganglia express catecholaminergic 

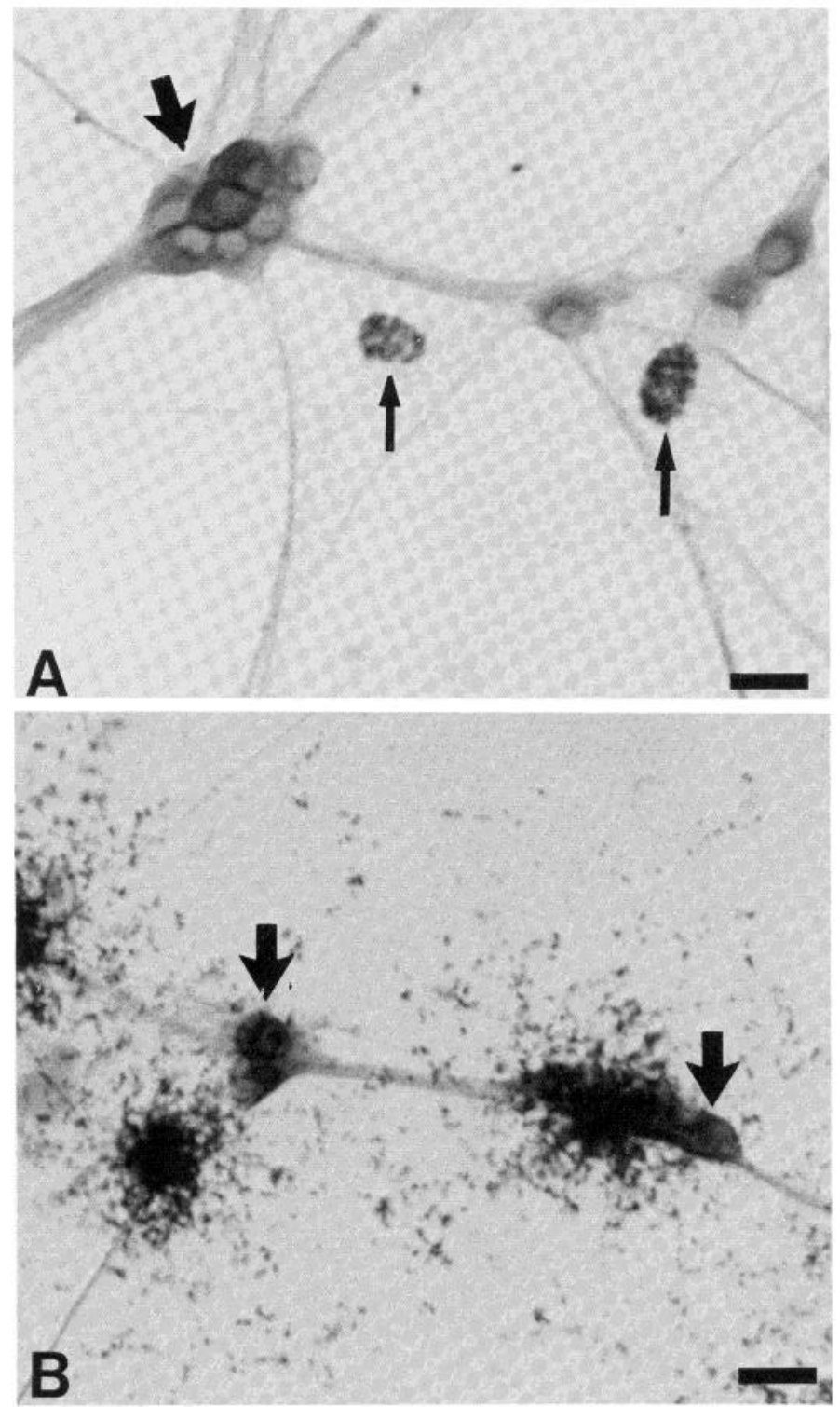

Figure 6. Combined $\left[{ }^{3} \mathrm{H}\right]$ thymidine radioautography and TH immunohistochemistry of chick ciliary neurons in vitro. Ciliary ganglia were removed, cultured for 5 days in the presence of $\left[{ }^{3} \mathrm{H}\right]$ thymidine $(A)$ or $\left[{ }^{14} \mathrm{C}\right]$ thymidine $(B)$, fixed, and processed for visualization of TH stain and silver grains. $A,\left[{ }^{3} \mathrm{H}\right]$ Thymidine labeling is seen over nuclei of unstained cells. Cells containing $\mathrm{TH}$ immunoreactivity do not have silver grains. $B$, Cultures incubated with $\left[{ }^{14} \mathrm{C}\right]$ thymidine. Stained neurons (arrow) are not labeled by the isotope. $B a r=20 \mu \mathrm{m}$.

traits during development in vivo and in vitro. We have found, using immunocytochemical techniques, that: $(a)$ small populations of CG neurons express TH but not PNMT in vivo; (b) neurons expressing TH or PNMT are found in CG when the ganglia is maintained in culture; $(c)$ the proportion of CG neurons expressing $\mathrm{TH}$ and PNMT increases dramatically when CG is grown in vitro in the presence of notochord; $(d)$ most CG neurons maintained in vitro with or without notochord probably contain AADC since they fluoresce after incubation with L-DOPA; and $(e)$ cells expressing CA enzymes in vitro are postmitotic. The fact that CG neurons are able to express CA enzymes after the time when the activity of the cholinergic enzyme, choline acetyltransferse, is first detected (LeDouarin et al., 1978), indicates that these cells remain labile with respect to their ability to synthesize neurotransmitter enzymes. However, since CG neurons do not contain endogeneous CAs, they apparently are able to express only some of the traits characteristic of the CA phenotype.

It is generally believed that neurons of the chick CG are uniformally cholinergic. In the present study, however, we found that $0.5 \%$ of neurons of the ganglion contain $\mathrm{TH}$ during development in vivo. This finding demonstrates that the ability to express the enzyme is intrinsic to at least some cells of the ganglia. In vitro, the proportion of CG neurons expressing $\mathrm{TH}$ increases since, in positive cultures, about $30 \%$ of the neurons are stained. This difference in the proportion of $\mathrm{TH}$ neurons in vivo and in vitro could be accounted for by selective survival and proliferation of the few neurons containing the TH in vivo once the ganglia are removed and placed in culture. This is, however, an unlikely possibility since neurons containing $\mathrm{TH}$ in vivo withdraw from the cell cycle at least 2 days prior to explantation of the ganglia. Thus, the majority of CG neurons that contain TH in vitro probably initiate the expression of this enzyme in response to cues present in the culture environment. Whether the role of environmental signals is to potentiate or to disinhibit TH synthesis remains to be determined.

Further evidence of the role of the environment on the appearance of CA traits in CG neurons is provided by the finding that the proportion of neurons expressing $\mathrm{TH}$ increases significantly when the ganglia is co-cultured with notochord. The notochord was selected because of studies supporting the contention that the appearance of a CA phenotype in neural crest cells and their neuronal derivatives required an interaction with this transient embryonic tissue (Cohen, 1972; Norr, 1973; Teillet et al., 1978). Our results, however, are in agreement with those of Cohen (1977) and indicate that the differentiation of adrenergic properties in the CG neurons occurs in the absence of cues released by the notochord. Thus, CG neurons contain $\mathrm{TH}$ in vivo despite the fact that the precursor cells of the ganglion have never interacted with notochord (Yntema and Hammond, 1947). This observation, taken together with the finding that the proportion of CG neurons containing TH increases in vitro and that it reaches almost $100 \%$ in the presence of notochord, suggests that this axial structure does not induce the appearance of novel traits but, as suggested by Lash (1968), facilitates the expression of preexisting ones. According to this hypothesis, all CG neurons in vivo contain TH, but in most of them the enzyme is present in undetectable levels. In vitro, the environment provided by the notochord raises the level of $\mathrm{TH}$, allowing its detection in most neurons present in the culture dish. This proposition implies that the environment present in vivo is least favorable while that provided by the notochord in vitro is most favorable for the expression of $\mathrm{TH}$ in CG neurons.

The observation that in vitro, the CG neurons express PNMT and that the proportion of neurons containing the enzymes increases dramatically when the ganglia is co-cultured with notochord indicates that, as with TH, the appearance of PNMT in CG neurons is enhanced by environmental signals. PNMT, however, is not observed in vivo. The enzyme may be present in vivo but at concentrations below the sensitivity of the immunocytochemical technique, as recently found in chick sympathetic neurons (Teitelman et al., 1984) and neurons of rat hypothalamus (Ross et al., 1984). Alternatively, the absence of PNMT in vivo may be an indication that CA traits are expressed by different cell types in vivo and in vitro or that the neurons that contain $\mathrm{TH}$ in vivo may initiate synthesis of PNMT after being transferred to culture.

Studies done on quail chick chimaeras had previously demonstrated that cells of the CG can express CA traits in response to environmental cues (LeDouarin et al., 1978). In this study, it was found that when the CG of a quail embryo was placed in the trunk neural axis of a younger chick embryo the ganglion cells migrate to populate sympathetic tissues where they ex- 

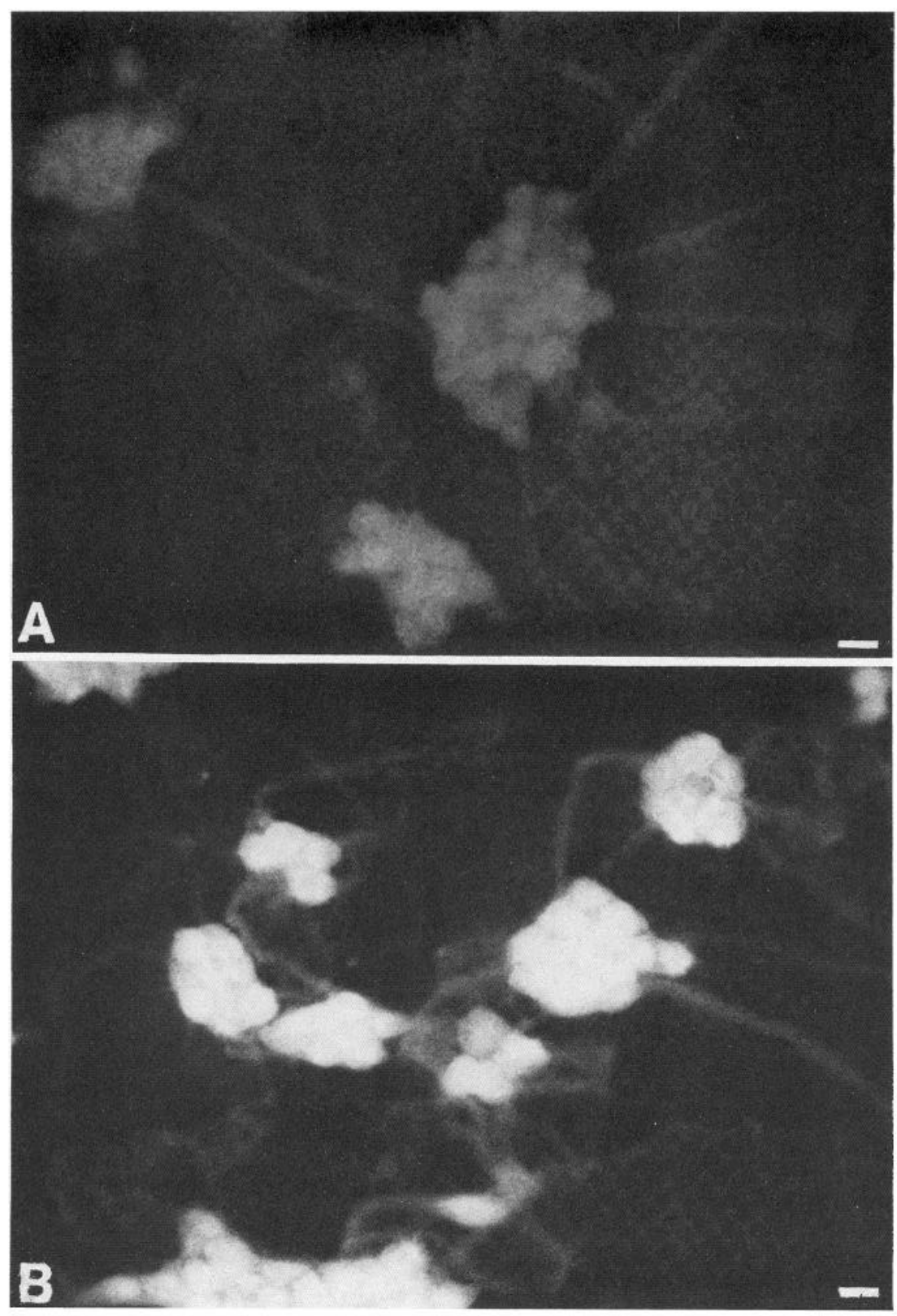

Figure 7. Catecholamine histofluorescence in CG neurons. $A$, Cultures incubated with vehicle (L-15) do not fluoresce. $B$, Cultures incubated with L-DOPA. Specific dopamine histofluorescence is seen in CG neurons but not in non-neuronal cells. $B a r=20 \mu \mathrm{m}$. press CA histofluorescence (LeDouarin et al, 1978). Since presumably the neurons of the back-transplanted CG do not survive in the environment of the host embryo, these authors postulated that the non-neuronal cells of the CG undergo phenotypic interconversion and initiate synthesis of catecholamines after migration (LeLievre and LeDouarin, 1982). This possibility is supported by recent findings that a subpopulation of non-neuronal cells of the CG display some CA traits such as a high affinity uptake of norepinephrine and receptors for nerve growth factor after 1 day in culture (Rohrer and Sommer, 1983). In our study, in contrast, it seems likely that the CA traits are expressed by neurons rather than non-neuronal cells of the ganglia since the cells containing $\mathrm{TH}$ in vitro do not incorporate labeled thymidine into their nuclei as would be expected if they originate from a proliferating precursor population. Although the difference between our results and those of LeDouarin et al. (1978) and Rohrer and Sommer (1983) may be due not only to different experimental approaches, but also the fact that different CA traits were investigated, they suggest that both neurons and non-neuronal cells of the CG are able to express at least some CA traits in response to environmental cues although different signals may determine the appearance of CAs in each cell type.

While environmental cues seem to facilitate the expression of TH and PNMT by CG neurons in vitro, those signals are not required for the appearance of dopamine histofluorescence in cultures incubated with L-DOPA. The fact that most CG neurons cultured alone or in the presence of notochord fluoresce after preincubation with L-DOPA suggests that the neurons contain AADC and that the enzyme is catalytically active in both culture conditions. The presence of CA histofluorescence in $\mathrm{CG}$ neurons after 3 days in vitro, 2 days before the appearance of TH and PNMT, indicates that the appearance of AADC is uncoupled in time with that of TH and PNMT, and may be regulated by different signals altogether. This contention is supported by the recent discovery of AADC in neurons that do not contain other CA enzymes (Jaeger et al., 1983). Although the fluorescent studies indicate that CG neurons in vitro are able to convert dopa into dopamine, apparently they cannot synthesize catecholamines from L-tyrosine. The possibility that 
$\mathrm{CG}$ neurons in vitro lack endogenous $\mathrm{CA}$ is suggested by the absence of histofluorescence in cultures incubated in media lacking L-DOPA. Conceivably, the molecular forms of $\mathrm{TH}$, the first enzyme of the CA pathway, could be catalytically inactive in the CG, thus rendering the neurons incapable of catecholamine synthesis. This possibility is supported by recent preliminary findings indicating the absence of TH enzymatic activity in CG neurons maintained in vitro (L. Iacovitti, T. H. Joh, D. J. Reis, and G. Teitelman, manuscript in preparation). Alternatively, CA neurons may contain endogenous catecholamines but at concentrations below levels detectable with the present technique.

The presence of the CG in vivo of cells containing $\mathrm{TH}$ demonstrates that the expression of CA traits is not restricted in the autonomic nervous system to catecholaminergic neurons of sympathetic organs. Moreover, the recent reports that neurons of sensory and cranial dorsal root ganglia of rat embryos express CA properties (Jonakait et al., 1984), indicates that the presence of CA neurons in non-CA neural crest derivatives of mammalian and chick embryos is a common occurrence. The fate of those cells containing $\mathrm{TH}$ in the $\mathrm{CG}$ in vivo remains to be determined. The expression of TH may be transient, as that of the transient catecholaminergic cells found in several organs of mouse and rat embryos (Cochard et al., 1978; Teitelman et al., 1978, 1981, a and b), or it may persist throughout development and in the adult. Cells containing $\mathrm{TH}$ and endogenous CA have been found in other non-CA ganglia in adult mammals (Katz et al., 1983; Price and Mudge, 1983). Indeed, a few neurons containing CA histofluorescence after L-DOPA treatment have been detected in the CG of adult rats (Ehinger and Falck, 1970).

The CG in vivo also contains nerve processes that stain with TH which may be similar to the fluorescent terminals described by others (Ehinger, 1967; Cantino and Mugnaini, 1974). These processes may be intrinsic or they may originate in the oculomotor nuclei of the brain, which is the only presynaptic input received by the $C G$. In rat, where fluorescent fibers have also been shown in the CG, ablation of the oculomotor nerve results in the disappearance of fluorescent fibers from the ganglia (Ehinger and Falek, 1970). The fact that this nucleus is cholinergic raises the possibility that $\mathrm{CA}$ enzymes are expressed by non-CA neurons not only in the peripheral nervous system, but also, in brain.

In summary, in this study we demonstrate that cholinergic neurons of the CG express CA traits both in vivo and in vitro and that the appearance of these properties is influenced by tissue environment. The fate of the cholinergic traits in CG neurons expressing a CA phenotype, however, remains to be determined. Conceivably, these traits may be lost once the neurons initiate synthesis of CA enzymes. This type of complete interconversion from one phenotype to another has been shown to occur in the population of transient catecholaminergic cells of mouse embryonic pancreas (Teitelman et al., 1981, a and b). These cells, which probably are still proliferating, give rise to the glucagon and insulin cells of the islets. Alternatively, the CG neurons that acquire $C A$ traits may retain the ability to synthesize cholinergic enzymes. Such a finding would indicate that the capacity for dual phenotypic expression is a characteristic of both sympathetic (Iacovitti et al., 1981; Wolinsky and Patterson, 1983) and parasympathetic postmitotic neurons of the autonomic nervous system.

\section{References}

Adler, R., K. Landa, M. Manthorpe, and S. Varon (1979) Cholinergic neuronotropic factors. II. Intraocular distribution of trophic activity for ciliary neurons. Science 204: 1434-1436.

Bancroft, M., and R. Bellairs (1976) The development of the notochord in the chick embryo; studied by scanning and transmission electron microscopy. J. Embryol. Exp. Murphol. 35: 383-401.

Bornstein, M. B. (1958) Reconstituted rat-tail collagen used as a substrate for tissue culture on cover slips in Maximow slides and roller tubes. Lab. Invest. 7: 134-137.

Bunge, R. P., and P. Wood (1973) Studies on the transplantation of spinal cord tissue in the rat. I. The development of a culture system for hemisections of embryonic spinal cord. Brain Res. 57: 261-276.

Bunge, R. P., M. Johnson, and C. D. Ross (1978) Nature and nurture in the development of autonomic neuron. Science 199: 1409-1416.

Cantino, D., and E. Mugnaini (1974) Adrenergic innervation of the parasympathetic ciliary ganglia in the chick. Science 185: 279-281.

Cochard, P., M. Goldstein, and I. B. Black (1978) Ontogenetic appearance and disappearance of tyrosine hydroxylase and catecholamines in the rat embryo. Proc. Natl. Acad. Sci. U. S. A. 75: 2986-2990.

Cohen, A. M. (1972) Factors directing the expression of sympathetic nerve traits in cells of neural crest origin. J. Exp. Zool. 179: 167-182.

Cohen, A. M. (1977) Independent expression of the adrenergic phenotype by neural crest cells in vitro. Proc. Natl. Acad. Sci. U. S. A. 74: $2899-2903$.

Ehinger, B. (1967) Adrenergic nerves in the avian eye and ciliary ganglion. Z. Zellforsch. 82: 577-588.

Ehinger, B., and B. Falck (1970) Uptake of some catecholamines and their precursors into neurons of the rat ciliary ganglion. Acta Physiol. Scand. 78: 132-141.

Furness, J. B., M. Costa, and W. W. Blessing (1977) Simultaneous fixation and production of catecholamine fluorescence in central nervous tissue by perfusion with aldehydes. Histochem. J. 9: 745750.

Furshpan, E. J., P. R. MacLeish, P. H. O'Lague, and D. D. Potter (1976) Chemical transmission between rat sympathetic neurons and cardiac myocytes developing in microcultures: evidence for cholinergic, adrenergic and dual-function neurons. Proc. Natl. Acad. Sci. U. S. A. 73: $4225-4229$.

Hamburger, V., and H. K. Hamilton (1951) A series of normal stages in the development of the chick embryo. J. Morphol. 88: 49-92.

Higgins, D., L. Iacovitti, H. Burton, and T. H. Joh (1981) The immunocytochemical localization of tyrosine hydroxylase within rat sympathetic neurons that release acetylcholine in culture. J. Neurosci. 1: $126-131$.

Iacovitti, L., T. H. Joh, D. H. Park, and R. P. Bunge (1981) Dual expression of neurotransmitter synthesis in cultured autonomic neurons. J. Neurosci. 1: 685-690.

Jaeger, C. B., G. Teitelman, T. H. Joh, V. R. Albert, D. H. Park, and D. J. Reis (1983) Some neurons of the rat central nervous system contain aromatic L-amino acid decarboxylase but not monoamines. Science 219: 1233-1235.

Joh, T. H., E. E. Baetge, M. E. Ross, V. R. Albert, and D. J. Reis (1984) Gene expression of catecholamine biosynthetic enzymes. In Coexistence of Neuroactive Substances in Neurons, V. Chan-Palay and S. L. Palay, eds., pp. 171-179, John Wiley and Sons, New York

Joh, T. H., and M. E. Ross (1983) Preparation of catecholamine synthesizing enzymes as immunogens for immunohistochemistry. In Immunohistochemistry. IBRO Handbook Series: Methods in the Neurosciences, A. C. Cuello, ed., Vol. 3, pp. 121-138, John Wiley and Sons, Ltd., Chichester, England

Jonakait, G. M., K. A. Markey, M. Goldstein, and I. B. Black (1984) Transient expression of selected catecholaminergic traits in cranial sensory and dorsal root ganglia of the embryonic rat. Dev. Biol. 101: $51-60$.

Katz, D. M., A. Markey, M. Goldstein, and I. B. Black (1983) Expression of catecholaminergic characteristics by peripheral sensory ganglion cells in the normal adult rat in vivo. Proc. Natl. Acad. Sci. U. S. A. 80 : $3526-3530$.

Laemmli, U. K. (1970) Cleavage of structural proteins during the assembly of the head of bacteriophage T4. Nature 227: 680-685.

Landmesser, L., and G. Pilar (1974) Synaptic transmission and cell death during normal ganglionic development. J. Physiol. (Lond.) 241: 738-750.

Lash, J. W. (1968) Somitic mesenchyme and its response to cartilage induction. In Epithelial Mesenchymal Interactions, R. Fleischmajer and R. E. Billingham, eds. Williams and Wilkins Co., Baltimore.

LeDouarin, N. M. (1980) The ontogeny of the neural crest in avian embryo chimaeras. Nature 286: 663-669.

LeDouarin, N. M., M. A. Teillet, C. Ziller, and J. Smith (1978) Adre- 
nergic differentiation of cells of the cholinergic ciliary and Remak ganglia in avian embryo following in vivo transplantation. Proc. Natl. Acad. Sci. U. S. A. 75: 2030-2034.

LeLievre, C. S. and N.M. LeDouarin (1982) The early development of cranial sensory ganglia and the potentialities of their component cells studied in quail-chick chimaeras. Dev. Biol. 94: 291-310.

Norr, S. C. (1.973) In vitro analysis of sympathetic neuron: differentiation from chick neural crest cells. Dev. Biol. 34: 16-38.

Patterson, P. H. (1978) Environmental determination of autonomic neurotransmitter function. Annu. Rev. Neurosci. 1: 117.

Pilar, G., L. Landmesser, and L. Burstein (1980) Competition for survival among developing ciliary ganglion cells. J. Neurophysiol. 43: 233-254.

Price, J., and A. W. Mudge (1983) A subpopulation of rat dorsal root ganglion neurons is catecholaminergic. Nature 301: 241-243.

Rogers, A. (1973) Techniques of Autoradiology. Elsevier Scientific Publishing Co., Amsterdam

Rohrer, H., and I. Sommer (1983) Simultaneous expression of neuronal and glial properties by chick ciliary ganglion cells during development. J. Neurosci. 3: 1683-1693.

Ross, C. A., D. A. Ruggiero, D. H. Park, M. P. Meeley, T. H. Joh, and D. J. Reis (1984) A new group of neurons in hypothalamus containing phenylethanolamine N-methyltransferase (PMNT) but not tyrosine hydroxylase. Brain Res. 306: 349-353.

Rothman, T. P., L. A. Specht, M. D. Gershon, T. H. Joh, G. Teitelman, V. M. Pickel, and D. J. Reis (1980) Catecholamine enzymes are expressed in replicating cells of the peripheral but not the central nervous system. Proc. Natl. Acad. Sci. U. S. A. 77: 6221-6225.

Sternberger, L. A. (1974) Immunocytochemistry. Prentice-Hall, Englewood Cliffs, NJ.
Teillet, M. A., P. Cochard, and N. M. LeDouarin (1978) Relative roles of the mesenchymal tissues and of the complex neural tube-notochord on the expression of adrenergic metabolism in neural crest. Zoon 6: 115-122.

Teitelman, G., 'T. J. Joh, and D. J. Reis (1978) 'Transient expression of a noradrenergic phenotype in cells of the rat embryonic gut. Brain Res. 158: 229-234.

Teitelman, G., M. D. Gershon, T. P. Rothman, T. H. Joh, and D. J. Reis (1981a) Proliferation and distribution of cells that transiently express a catecholaminergic phenotype during development in mice and rats. Dev. Biol. 86: 348-355.

Teitelman, G., T. H. Joh, and D. J. Reis (1981b) Transformation of catecholaminergic precursors into glucagon (A) cells in mouse embryonic pancreas. Proc. Natl. Acad. Sci. U. S. A. 78: 5225-5229.

Teitelman, G., S. Skaper, H. Baker, D. H. Park, T. H. Joh, and R. Adler (1984) Expression of phenylethanolamine N-methyltransferase in sympathetic neurons and extradrenal chromaffin tissue of chick embryo in vivo and in vitro. Dev. Brain Res. 13: 283-291.

Towbin, H., T. Staechelin, and J. Gordon (1979) Electrophoretic transfer of proteins from polyacrylamide gels to nitrocellulose sheets: procedure and some applications. Proc. Natl. Acad. Sci. U. S. A. 76 : $4350-4354$

Varon, S., M. Manthorpe, and R. Adler (1979) Cholinergic neuronotrophic factors. I. Survival, neurite outgrowth and choline acetyltransferase activity in monolayer cultures from chick embryo ciliary ganglia. Brian Res. 173: 29-45.

Wolinsky, E., and P. A. Patterson (1983) Tyrosine hydroxylase activity decreases with induction of cholinergic properties in cultured sympathetic neurons. J. Neurosci. 3: 1495-1500.

Yntema, C. I., and W. S. Hammond (1947) The development of the autonomic nervous system. Biol. Rev. Camb. Phil. Soc. 22: 344-359. 